Haya: The Saudi Journal of Life Sciences

Abbreviated Key Title: Haya Saudi J Life Sci

ISSN 2415-623X (Print) |ISSN 2415-6221 (Online)

Scholars Middle East Publishers, Dubai, United Arab Emirates

Journal homepage: https://saudijournals.com/sjls

Original Research Article

\title{
Socio-Economic and Demographic Influences on Body Mass Index and Thinness among Rural Tribal Adolescent Boys of Kharagpur, West Bengal, India
}

\author{
Pijush Kanti Roy ${ }^{1}$, Gopal Chandra Mandal ${ }^{2 *}$, and Kaushik Bose ${ }^{3}$ \\ ${ }^{1}$ M. Phil scholar, Dept. of Anthropology, Vidyasagar University, Paschim Midnapore, WB, India \\ ${ }^{2}$ Associate Professor and Head, Dept. of Anthropology, Bangabasi College, Kolkata, India \\ ${ }^{3}$ Professor, Dept. of Anthropology, Vidyasagar University, Paschim Midnapore, WB, India
}

DOI: $10.36348 /$ sjls.2020.v05i09.004 $\quad$ | Received: 29.08.2020 | Accepted: 04.09.2020 | Published: 24.09.2020

*Corresponding author: Dr. Gopal Chandra Mandal

\section{Abstract}

Adolescent is a transitional phase between childhood and adulthood characterized by marked acceleration in growth. Undernutrition is one of the major problems especially among the tribal adolescent boys and it has been least studied. Hence, the objective of the present study was to evaluate the association of socio-economic and demographic aspects with BMI and prevalence of thinness (low BMI for age) among the tribal adolescent boys. This cross-sectional study was conducted among 370 tribal adolescent boys, aged 10-17 years from Kharagpur Community Development Block II, West Midnapore, and West Bengal, India. Assessment of nutritional status as measured by thinness (Low BMI for age) was done following age and sex specific internationally accepted standard cut offs as proposed by Cole and others (2007). Linear regression was applied to evaluate the dependence of BMI on various socio-economic factors of the participants. The overall prevalence of thinness was $51.6 \%$. When age specific prevalence are taken into account, the highest (63.6\%) prevalence was found among the participants of the age group of 10 years, followed by age group $11(61.9 \%)$ and lowest in case of 16 years (40.0\%). 1.6\% boys were overweight or obese. Fathers' education, fathers' and mothers' occupation as well as family type were significant $(\mathrm{p}<0.05)$ factors which influenced their BMI. These tribal adolescent boys were experiencing severe nutritional stress as evidenced by a very high prevalence of thinness. Appropriate and effective nutritional interventions are needed to ameliorate their nutritional status.

Keywords: Body mass index; thinness, tribal, adolescents, boys, West Bengal.

Copyright @ 2020: This is an open-access article distributed under the terms of the Creative Commons Attribution license which permits unrestricted use, distribution, and reproduction in any medium for non-commercial use (NonCommercial, or CC-BY-NC) provided the original author and source are credited.

\section{INTRODUCTION}

Adolescence is the phase which is marked by the beginning of signs of emergence of secondary sexual characters and continues up to the morphological and physiological maturation to move to the adulthood and it is considered from age 10-19 years [1] and is a transitional phase between childhood and adulthood characterized by marked acceleration in growth $[2,3]$. This period is known to be a second chance for growth or catch-up growth for those children who have experienced a nutritional deficit in their early life $[4,5]$. These are the formative years in the life of an individual [6]. It is an age for making our future generation healthy [7]. Recent reports of the World Health Organization suggest that in South East Asian Region a large number of adolescents, who constitute $20 \%$ of the population in these countries, suffer from malnutrition and anemia, which adversely impacts their health and development [2].

According to the Census, Govt. of India [8] the tribal population constitutes $8.6 \%$ of its total population. The tribal populations are among the most underprivileged and undernourished people in India. $93.0 \%$ of this population resides in rural areas which are significantly underdeveloped areas, thus having disadvantage than other categories of the population in terms of economy, education, health, medical facilities etc. West Bengal is inhabited by substantial number of scheduled tribe population, having 40 schedule tribes like Santhal, Munda, Bhumij, Oraon, Mahali, Mech, Sabar and others [9]. The growth and nutritional status of the children of various sections of Indian population have been assessed but the information about the tribal population in this regard is very limited. 
Anthropometry provides insights of relationship between biological and social factors as several studies established that growth differences of adolescents among group are related to nutritional status, socioeconomic levels, residents and degree of industrialization and urbanization [1]. Several factors affect the nutritional status of adolescents. Among these, socio-economic and demographic factors are associated with worldwide patterns of stunting and thinness. It has also been seen that the variability among nations and regions was substantial in comparison with variability among individuals within provinces [10].

Although nutritional status of adolescent boys, the future fathers, contributes significantly to the nutritional status of the community, assessment of nutritional status of adolescents has been the least investigated area of research particularly in rural and tribal areas of India. Hitherto, to the best of our knowledge, there are no previous studies dealing with thinness among adolescent tribal boys of Kharagpur region, Paschim Medinipur, West Bengal. This is the uniqueness of our study.

\section{OBJECTIVES}

Studying adolescent group is of immense importance as their health and education today, determines the economical background of the nation in future. Hence, the objective of the present study was to evaluate the association of socio-economic and demographic aspects with BMI and prevalence of thinness (low BMI for age) among the tribal adolescent boys.

\section{MATERIALS AND METHODS}

\section{The area}

The Kharagpur Community Development Block -II is situated $10 \mathrm{~km}$. south of the District Head Quarter, Paschim Midnapore, West Bengal, India, where, this cross-sectional study was conducted in Higher Secondary Schools of 10 villages around Kharagpur town. Tribal groups like Santhal, Munda, Bhumij, Mahali, Sabar constitute $25.6 \%$ of the total population of the Block.

\section{The participants}

Anthropometric measurements and socioeconomic and demographic information were collected from 370 tribal adolescent boys, aged 10-17 years. The students were randomly selected from who were present on the days of work. The living amenities were more or less same for all the groups. Hence, we considered them as a single term 'tribal group'. Age of the participants was calculated from the DOB recorded in the school registration books. The participants were selected only from tribal communities.

\section{Anthropometric measurements}

Height $(\mathrm{cm})$ and weight $(\mathrm{kg})$ were measured following standard method [11]. Measurements were taken by the first author. BMI $\left(\mathrm{kg} / \mathrm{m}^{2}\right)$ was calculated following standard equation [1]. The technical error of measurements (TEM) was calculated for height and weight and they were found to be within reference values as given by Ulijaszek \& Kerr [12]. Thus, TEM were not incorporated in any analyses.

\section{Assessment of thinness}

Assessment of nutritional status as measured by thinness (Low BMI for age) was done following age and sex specific internationally accepted standard cut offs as proposed by Cole and others [13]. All the undernourished adolescents were categorized as Grade I, II, and III for severity of thinness.

Table-1: The age specific cut-off points (boys) for thinness (Cole et al., 2007)

\begin{tabular}{|l|l|l|l|}
\hline \multirow{2}{*}{$\begin{array}{c}\text { Age } \\
\text { (years) }\end{array}$} & \multicolumn{3}{|c|}{ Thinness } \\
\cline { 2 - 4 } & Grade III & Grade II & Grade I \\
\hline 10 & 12.66 & 13.45 & 14.65 \\
\hline 11 & 12.89 & 13.72 & 14.97 \\
\hline 12 & 13.18 & 14.05 & 15.35 \\
\hline 13 & 13.59 & 14.48 & 15.84 \\
\hline 14 & 14.09 & 15.01 & 16.41 \\
\hline 15 & 14.60 & 15.55 & 16.98 \\
\hline 16 & 15.12 & 16.08 & 17.54 \\
\hline 17 & 15.60 & 16.58 & 18.05 \\
\hline
\end{tabular}

\section{Socio-economic and demographic information}

Socio-economic and demographic aspects i.e. ethnicity, literacy, economic aspects of family, types of family, physical activities performed by the respondents were collected through structured questionnaire. The fathers' and mother's education were categorized as (1 = illiterate, 2 =primary, $3=$ secondary, $4=$ higher secondary and above). Father's occupation was categorized as 1 = manual labour (day labour, mason, carpenter, driver etc.), non-manual labour (Service, business etc.), 3 = land holder. Mother's occupation was coded as: 1 = house work, 2 = manual labour and 3 = non-manual labour. In case of physical activity, it was categorized as $1=$ yes and $2=$ no. Types of family had been coded as 1 stands for nuclear whereas, 2 stands for joint family.

\section{STATISTICAL ANALYSIS}

All essential descriptive and inferential statistics were done by Statistical Package for Social Sciences (SPSS) version 16.0. Descriptive statistics (mean, standard deviation) for the continuous variable were computed. For comparing the mean of the variables between age-groups one way analysis of variance (ANOVA) was computed. Linear regression was applied to evaluate the dependence of BMI on various socio-economic factors of the participants. Statistical significance was set as $\mathrm{p}<0.05$. 


\section{Ethical approval}

Ethical approval was taken from the Ethical and Research Committee of Department of Anthropology, Vidyasagar University. Permission for conducting the study was also obtained from each school authority. Informed consent was obtained from each participant as well.

\section{RESULTS}

Table-2: Mean (SD) of height $(\mathrm{cm})$, weight $(\mathrm{kg})$ and BMI $\left(\mathrm{kg} / \mathrm{m}^{2}\right)$ of the participants

\begin{tabular}{|c|c|c|c|c|c|c|c|c|c|c|}
\hline \multirow[t]{2}{*}{ Variables } & \multicolumn{8}{|c|}{ Age (Years) } & Overall & $\mathbf{F}$ \\
\hline & $\begin{array}{l}10 \\
(\mathrm{~N}=55)\end{array}$ & $\begin{array}{l}11 \\
(\mathrm{~N}=42)\end{array}$ & $\begin{array}{l}12 \\
(\mathrm{~N}=54)\end{array}$ & $\begin{array}{l}13 \\
(\mathrm{~N}=52)\end{array}$ & $\begin{array}{l}14 \\
(\mathrm{~N}=43)\end{array}$ & $\begin{array}{l}15 \\
(\mathrm{~N}=39)\end{array}$ & $\begin{array}{l}16 \\
(\mathrm{~N}=45)\end{array}$ & $\begin{array}{l}17 \\
(\mathrm{~N}=40)\end{array}$ & $\mathrm{N}=370$ & \\
\hline Height & $\begin{array}{l}131.0 \\
(7.5)\end{array}$ & $\begin{array}{l}135.6 \\
(6.0)\end{array}$ & $\begin{array}{l}140.5 \\
(8.4)\end{array}$ & $\begin{array}{l}147.7 \\
(7.6)\end{array}$ & $\begin{array}{l}152.8 \\
(10.7)\end{array}$ & $\begin{array}{l}152.9 \\
(9.2)\end{array}$ & $\begin{array}{l}160.3 \\
(6.5)\end{array}$ & $\begin{array}{l}160.4 \\
(7.8)\end{array}$ & $\begin{array}{l}146.8 \\
(13.1)\end{array}$ & $87.9 *$ \\
\hline Weight & $\begin{array}{l}24.4 \\
(4.3)\end{array}$ & $\begin{array}{l}27.8 \\
(5.2)\end{array}$ & $\begin{array}{l}31.1 \\
(6.5)\end{array}$ & $\begin{array}{l}36.0 \\
(4.2)\end{array}$ & $\begin{array}{l}40.0 \\
(7.0)\end{array}$ & $\begin{array}{l}39.4 \\
(8.8)\end{array}$ & $\begin{array}{l}47.4 \\
(8.0)\end{array}$ & $\begin{array}{l}47.0 \\
(7.0)\end{array}$ & $\begin{array}{l}36.1 \\
(10.3)\end{array}$ & $78.5^{*}$ \\
\hline BMI & $\begin{array}{l}14.13 \\
(1.4) \\
\end{array}$ & $\begin{array}{l}15.03 \\
(1.9)\end{array}$ & $\begin{array}{l}15.6 \\
(2.0)\end{array}$ & $\begin{array}{l}16.4 \\
(2.1)\end{array}$ & $\begin{array}{l}17.1 \\
(2.4)\end{array}$ & $\begin{array}{l}16.8 \\
(2.6)\end{array}$ & $\begin{array}{l}18.4 \\
(2.2)\end{array}$ & $\begin{array}{l}18.3 \\
(2.0)\end{array}$ & $\begin{array}{l}16.3 \\
(2.5) \\
\end{array}$ & $24.4^{*}$ \\
\hline
\end{tabular}

Table 2 represents the mean (SD) and the age trends of the variables among the studied adolescent tribal boys. Mean height among them was $146.8 \mathrm{~cm}$ (13.1) and weight was $36.1 \mathrm{~kg}$ (10.3). In case of BMI it was 16.3 (2.5). The highest mean value of height (160.4 $\mathrm{cm}$ ) was noticed at 17 years of age and lowest mean value of height $(131.0 \mathrm{~cm})$ was noticed at 10 years of age. The highest mean weight $(47.4 \mathrm{~kg})$ was noticed at 16 years of age and lowest mean weight $(24.4 \mathrm{~kg})$ was noticed at 10 years of age. It is also evident from this table that the values of the variables were increasing with the increase of the age of the participants (excepting in few age groups) and this gradual increase was highly significant when evaluated through ANOVA ( $p<0.001)$. The maximum increase in height was found at age group 15-17 years, reflecting boy's adolescent growth spurt.

Table-3: Prevalence of thinness based on Cole et al. cut offs (2007)

\begin{tabular}{|c|c|c|c|c|c|c|}
\hline \multirow[t]{2}{*}{ Age } & \multicolumn{4}{|c|}{ Thinness } & & \multirow{2}{*}{$\begin{array}{l}\text { Overweigh } \\
\text { /obese }\end{array}$} \\
\hline & Grade III & Grade II & Grade I & Total & Normal & \\
\hline $10(\mathrm{~N}=55)$ & 8 & 12 & 15 & $35(63.6)$ & $20(36.4)$ & \\
\hline $11(\mathrm{~N}=42)$ & 3 & 6 & 17 & $26(61.9)$ & $15(35.7)$ & $1(2.4)$ \\
\hline $12(\mathrm{~N}=54)$ & 4 & 4 & 19 & $27(50.0)$ & $25(46.3)$ & $2(3.7)$ \\
\hline $13(\mathrm{~N}=52)$ & 2 & 5 & 16 & $23(44.2)$ & $28(53.8)$ & $1(1.9)$ \\
\hline $14(\mathrm{~N}=43)$ & 1 & 7 & 10 & $18(41.9)$ & $24(55.8)$ & $1(2.3)$ \\
\hline $15(\mathrm{~N}=39)$ & 6 & 9 & 7 & $22(56.4)$ & $17(43.6)$ & - \\
\hline $16(\mathrm{~N}=45)$ & 4 & - & 14 & $18(40.0)$ & $26(57.8)$ & $1(2.2)$ \\
\hline $17(\mathrm{~N}=40)$ & 3 & 5 & 14 & $22(55.0)$ & $18(45.0)$ & - \\
\hline $\begin{array}{l}\text { Total } \\
(\mathrm{N}=370)\end{array}$ & $31(8.4)$ & $48(13.0)$ & $112(30.2)$ & $191(51.6)$ & $173(46.8)$ & $6(1.6)$ \\
\hline
\end{tabular}

Table 3 shows the prevalence of thinness (low BMI for age) using cut off (Table 2) as proposed by Cole and others (2007) along with the three Grades. From the table, it is evident that the overall prevalence of thinness was $51.6 \%$. The highest frequency was noticed in case of Grade I category $(30.2 \%)$ followed by moderate (Grade II, 13.0\%) and severe thin (Grade III) adolescents were $8.4 \%$. When age specific prevalence are taken into account, the highest (63.6\%) prevalence was found among the participants of the age group of 10 years, followed by age group $11(61.9 \%)$ and in case of 17 years $(55.0 \%)$. The lowest prevalence $(40.0 \%)$ was found in the age group of 16 years. From this table it is also evident that, overall $1.6 \%$ boys were overweight or obese. 
Table-4: Linear regression analysis: effect of socio-economic and demographic factors on BMI

\begin{tabular}{|l|l|l|l|l|l|l|}
\hline Independent Variables & $\mathbf{B}$ & \multicolumn{1}{|c|}{ SeB } & $\begin{array}{c}\text { CI } \\
\mathbf{( 9 5 \% )}\end{array}$ & \multicolumn{1}{|c|}{ Beta } & \multicolumn{1}{|c|}{ Remarks } \\
\hline Father's education & 0.275 & 0.131 & $0.017-0.533$ & 0.109 & $2.100^{*}(0.036)$ & Significant \\
\hline Father's occupation & 0.384 & 0.140 & $0.072-0.624$ & 0.128 & $2.497^{*}(0.014)$ & Significant \\
\hline Mother's education & 0.099 & 0.147 & $-.190-0.388$ & 0.035 & $0.676(0.500)$ & Not significant \\
\hline Mother's occupation & 0.549 & 0.240 & $0.078-1.020$ & 0.119 & $2.297^{*}(0.022)$ & Significant \\
\hline Physical activity & 0.654 & 1.030 & $-.371-2.678$ & 0.033 & $0.635(0.526)$ & Not significant \\
\hline Family type & -0.571 & 0.0 .279 & $-.119-0.023$ & -0.106 & $-2.047^{*}(0.041)$ & Significant \\
\hline \multicolumn{7}{|c|}{$*=\mathrm{p}<0.05$} \\
\hline
\end{tabular}

The results of the linear regression analysis and the association of socio-economic and demographic variables like fathers' and mothers' education and occupations; family types, physical activities performed by the participants on BMI are presented in Table 4 . It is evident that the BMI was significantly $(\mathrm{p}<0.05)$ associated and dependent on four out of six aspects of socio-economic and demographic variables. Father's and mother's occupation as well as father's education levels proved to be positively significant influence on BMI, whereas, not mother's education. In case of types of family it was negatively significant.

\section{DISCUSSION}

Although, improvements in health indicators like decline of fertility and infant mortality rates have been noticed in our county but the improvements in the nutritional aspects it was not so marked [14, 15]. More than half of the world's undernourished population lives in India [16]. Undernutrition is an indicator of poor nutrition and poor health of a population. However, very little information is available on the nutritional status of adolescents from rural areas of West Bengal. This lack of useful epidemiological data is the reason why we have attempted to investigate the nutritional status of adolescents from the rural areas of West Bengal state [17].

Our study area Kharagpur Community Development Block II is a rural based habitation and the tribal groups constitute $25.6 \%$ of the total population of the Block. Various tribal communities live in this area and their living conditions are similar. Hence, they were considered as a common community and mentioned here as 'tribal group'. All children and adolescents study in schools in and around their villages.

Mean height $(146.8 \mathrm{~cm})$ and BMI $(16.3 \mathrm{~kg} /$ $\mathrm{m}^{2}$ ) of the present adolescent boys were much higher than the Santhal adolescent boys $(134.8 \mathrm{~cm}$ and 15.6 respectively) from Purulia, West Bengal. But the mean weight $(36.1 \mathrm{~kg}$ and $36.1 \mathrm{~kg}$ ) was same between these two populations [18]. The mean height $(134.2 \mathrm{~cm})$, weight $(29.9 \mathrm{~kg})$ and BMI $\left(15.6 \mathrm{~kg} / \mathrm{m}^{2}\right)$ of the adolescent boys of Kolam tribe of Telengana state were much lower than the mean values of the present participants [19]. In a study among the rural male adolescent from Naxalbarih, Darjeeling District, West
Bengal, India done by Dey and others [14] found that the height $(154.4 \mathrm{~cm})$, weight $(42.0 \mathrm{~kg})$ and BMI $(17.7$ $\mathrm{kg} / \mathrm{m}^{2}$ ) were much higher than the participants of the present study.

However, in comparison of the rural adolescent boys of West Bengal studied by Pal and others [17] the mean values of the present adolescent boys were slightly lower in all three variables.

The overall prevalence of thinness (low BMI for age) among the studied participants was $51.6 \%$. The prevalence was found to be higher among girls of lower age groups and didn't show gradual decrease with increased age, rather in oscillating manner. Hill Kheria boys of Purulia District showed more or less similar prevalence $(52.1 \%)$ of thinness [20]. Whereas, the Santal boys of the same District showed much lower (38.2\%) prevalence [18]. Comparatively lower prevalence were also observed among the tribal adolescents from Paschim Medinipur (45.0\%) [9] and $45.1 \%$. [21]. In comparison to this prevalence, much higher prevalence had been observed among the Birhor children and adolescents (75.0\%) of the Purulia district, West Bengal [22].

Comparing with tribal adolescents of other states, high $(63.0 \%)$ prevalence of thinness has been observed among tribal adolescents of 9 states consist of Andhra Pradesh, Gujrat, Karnataka, Kerala, Madhya Pradesh, Maharashtra, West Bengal, Tamil Nadu, Orissa [23]. Higher prevalence were also found among the Kolam tribe (62.9\%) of Andhra Pradesh [19] and Sabar adolescents $(54.4 \%)$ of Orissa [24], while tribal children and adolescents of Tripura [25] showed lower prevalence $(28.5 \%)$. Slightly higher rate $(59.5 \%)$ was observed among the adolescent boys of tea garden workers of Assam [26]. The South Indian adolescent boys showed [27] much higher (64.6\%) prevalence of thinness than the adolescent boys of the present study.

Six socio-economic and demographic aspects of these tribal adolescent boys have been considered to evaluate the effect on BMI. In case of father's occupation, $29.2 \%$ of the total participants were undernourished whose father was engaged as manual labour force, followed by non-manual labour force having 5.9\% thin adolescents and fathers having own agricultural land showed $17.0 \%$ undernourished 
children. Whereas, in case of mother's occupation, $25.7 \%$ participants were thin whose mothers were engaged in household works, followed by manual labour and non-manual labour having $25.1 \%$ and $1.4 \%$ undernourished boys respectively. Coming to the case of fathers' education, we categorized as non-literate, primary, secondary and higher secondary and above and the prevalence of thinness were $25.1 \%, 7.3 \%$, $17.6 \%$, and $2.2 \%$ respectively. The prevalence of thin adolescent boys associated with mother's occupation were $33.8 \%, 5.1 \%, 12.4 \%$ and $0.8 \%$ respectively for the same categories as of fathers. Father's and mother's occupation and father's education showed significant contribution on thinness. The boys who lived in nuclear families showed $36.7 \%$ whereas $15.4 \%$ were not lived in nuclear families. Physical activities were another factor which had considered evaluating the effect on thinness. Boys who were involved in physical activities showed much higher prevalence of thinness of $51.3 \%$. Participants who did not engage in any physical activity displayed only $0.8 \%$ of thinness. This may be due to the consumption of inadequate amount of food which could supplement their energy loss.

Several socio-economic and demographic factors proved to be highly associated $(\mathrm{p}<0.001)$ with the BMI of the studied adolescent tribal boys. These factors were father's and mother's occupation and father's education; family types. That indicates the low BMI for age of these students were also affected by these factors. An earlier study had also reported similar results among the rural adolescents from West Bengal [17]. Adolescents with higher educated parents were less likely to be undernourished. Women not having higher education resulting in less exposure to the outside world are not aware of personal hygiene and wellbeing of the children. Educational exposure enables mothers to have greater access to household resources that are important for nutritional aspects [28]. Tesfaye [29] reported that some of the predictors of children nutritional status were maternal education, occupation of mother. Sapkota and Gurung [30] studied the nutritional status of the Nigerian children and concluded that the significant association of mother's education and undernutrion was also informed. Adolescents in Aksum Town, Northern Ethiopia also revealed the significant association of mother's educational status and thinness [31].

\section{CONCLUSION}

These tribal adolescent boys were experiencing severe nutritional stress as evidenced by a very high prevalence of thinness. Fathers' education, fathers' and mothers' occupation as well as family type were significant factors which influenced their BMI. Appropriate and effective nutritional interventions are needed to ameliorate their nutritional status.

\section{ACKNOWLEDGEMENTS}

All subjects who participated in the study are gratefully acknowledged. Special thanks are due to the parents and the school authorities for their kind cooperation and help.

\section{REFERENCES}

1. World Health Organization. (1995). Physical Status: The Use and Interpretation of Anthropometry: Technical report, No. 854. Geneva.

2. World Health Organization. (2005). Adolescents Nutrition: A review of the situation is selected South - East Asian countries World Health Organization. Regional office of South East Asia. 29 Dec 2005. Executive Summary.

3. Anand, K., Kant, S., \& Kapoor, S. K. (1999). Nutritional Status of Adolescents school children in rural north India. Indian Pediatr, 36, 810-5.

4. Rao, S. (2001). Nutritional Status of Indian population. J Biosci, 26, 481-9.

5. Delisle, H., Chandra-Mauli, V., \& Benoist, Bde. (2005). Should Adolescents be specifically targeted for nutrition in developing countries? To address which problems and how? WHO, Available from: http://www. Who.int/child-adolescent. [Accessed on 20.07.2020].

6. Patil, S.N., Wasnik,V., Wadke, R. (2009). Health Problems amongst Adolescent Girls in Rural Areas of Ratnagiri District of Maharastra, India. J Clin Diagn Res, 3, 1784-1790.

7. Puwar, T., Saxena, D. (2016). Use of IAP BMI standards for measuring nutritional status of adolescents in India. Letter to the Editor, National Journal of Community Medicine, 7(6), 545.

8. Census of India. (2011). Office of the Registrar General and Census Commissioner. Ministry of Home Affairs, Govt. of India. Available from: http://www.censusindia.gov.in (Accessed on March 20, 2020).

9. Dutta Chowdhury, S., Chakraborty, T., \& Ghosh, T. (2008). Prevalence of undernutrition in Santal children of Puruliya district, West Bengal. Indian Pediatr, 45(1), 43- 46.

10. Frongillo, E.A. Jr., de Onis, M., Kath Leon, M.P., \& Hanson, K. M. (1997). Socioeconomic and demographic factors are associated with worldwide patterns of stunting and wasting of children. J Nutr, 127, 2302-9.

11. Lohman, T.G., Roche, A.F., \& Martorell, R. (1988). Anthropometric Standardization Reference Manual. Chicago: Human Kinetics Books.

12. Ulijaszek, S.J., \& Kerr, D.A. (1999). Anthropometric measurement error and the assessment of nutritional status. Brit J Nutr, 82, $165-177$.

13. Cole, T.J., Flegal, K.M., Nicholls, D., \& Jackson, A.A. (2007). Body mass index cut offs to define thinness in children and adolescents: international survey. BMJ, 335, 194-202. 
14. Dey, I., Biswas, R., Ray, K., Bhattacherjee. S., Chakraborty, M., \& Pal, P.P. (2011). Nutritional status of school going adolescents in a rural block of Darjeeling, West Bengal, India. The Health, 2(3), 75-77.

15. Dutta Banik, S., Bhattacharjee, P., Mukhopadhyay, B. (2016). Low height-for-age among Limbu and Mech children and adolescents from two districts of West Bengal, India. Epidemiol biostat public health, 21, 13(4),1-12.

16. Roy, S., Barman, S., Mondal, N., \& Sen, J. (2016). Prevalence of stunting and thinness among adolescent girls belonging to Rajbanshi population of West Bengal, India. J Nepal Paediatr Soc, 36(2), 147-155.

17. Pal, A., Pari, A.K., Sinha, A., \& Dhara, P.C. (2017). Prevalence of undernutrition and associated factors: A cross-sectional study among rural adolescents in West Bengal, India. International Journal of Pediatrics and Adolescent Medicine, 4, 9e18.

18. Das, S., \& Bose, K. (2011a). Prevalence of thinness using new international cut-off points among Santal tribal children and adolescents of Purulia District, West Bengal, India. Sri Lanka Journal of Child Health, 40(3), 105-110.

19. Karri, B., Ghritlahre, M., Das, S., \& Bose, K. (2017). Nutritional status among children and adolescents aged 6-18 years of Kolam tribe of Andhra Pradesh, India. Anthrop Rev, 80,153-163.

20. Das, S., Bose, K. (2011b). Thinness among Hill Kharia children and adolescents of Purulia using Body Mass Index Cut-off points. RRJoHP, 1(2), 31-36.

21. Maiti, S., Ghosh, D., \& Paul, S. (2012). Determinants of Nutritional Status among Tribal Adolescent girls in Paschim Medinipur district of West Bengal. Int J Prev Med, 3(4), 298-299.
22. Das, S., Mahata, M., \& Bose, K. (2012). Age-trend in thinness among Birhor Children and Adolescents of Purulia: A Primitive Tribe of West Bengal, India. Asian J Biol life Sci, 1(1), 58-60.

23. Rao, K.M., Balakrishna, N., Laxmaiah, A. (2006). Diet and Nutritional Status of Adolescent Tribal Population in 9 States of India. Asia Pac J Clin Nutr, 15(1), 64-71.

24. Chakrabarty, S., \& Bharati, P. (2008). Physical Growth and Nutritional Status of the Shabar Tribal Adolescents of Orissa, India: a Cross-sectional Study. Malays J Nutr, 14(1), 101-112.

25. Sil, S.K., Sarkar, S.R., Saha, S., \& Roy, S. (2011). Assessment of nutritional status of rural tribal children in Tripura. Indian Pediatr, 48(6), 488-489.

26. Medhi, G.K., Hazarika, N.C., \& Mahanta, J. (2007). Nutritional status of adolescents among tea garden workers. Indian Journal of Pediatrics, 74(4), 343-7.

27. Haboubi, G.J., \& Shaikh, R.B. (2009). A Comparison of the Nutritional Status of Adolescents from Selected Schools of South India and UAE: A Cross-sectional Study. Indian Journal of Community Medicine, 34(2), 108-111.

28. Das, S., \& Sahoo, H. (2011). An investigation into factors affecting child undernutrition in Madhya Pradesh. Anthropologist, 13, 227e33.

29. Tesfaye, M. (2009). Bayesian approach to identify predictors of children Nutritional status in Ethiopia.

30. Sapkota, V.P., \& Gurung, C.K. (2009). Prevalence and predictors of underweight, stunting and wasting in under-five children. Nepal Health Res Counc, 7, $120 \mathrm{e} 6$.

31. Amha, A., \& Girum, T. (2018). Prevalence and associated factors of thinness among adolescent girls attending governmental schools in Aksum Town, Northern Ethiopia. Med J DY Patil Vidyapeeth, 11,158-64. 